\title{
Analysis of Five Leg Voltage Source Inverter Fed Dual Motor Drive System
}

\author{
Harish. S P ${ }^{1}$, Sridhar. $\mathrm{S}^{2}$, Omsekhar Indela ${ }^{3}$, Kodeeswara Kumaran. $\mathrm{G}^{2}$ and $P$. Parthiban ${ }^{4}$ \\ ${ }^{1}$ PG Student, EEE Dept., M S Ramaiah Institute of Technology, Bangalore \\ ${ }^{2}$ Associate Professor, EEE Dept., M S Ramaiah Institute of Technology, Bangalore \\ ${ }^{3}$ Assistant Professor, EEE Dept., M S Ramaiah Institute of Technology, Bangalore \\ ${ }^{4}$ Associate Professor, EEE Dept., National Institute of Technology- Surathkal, Karnataka
}

\begin{abstract}
With the advent of electric vehicle multi-machine drives are attaining overwhelming responses from the researchers and industries in recent years, as compared to their counterpart of single machine drive. In this regard, the industries are looking for multi motor control with single inverter system with precise speed control. The solution of aforesaid problem lies with multi-leg inverter fed dual induction motor drives that are capable for high power ratings and other specific applications. Any faults in the system leads to the failure of the operation of the entire drive system. Hence condition monitoring of the entire drive system becomes of paramount significance. Considering the aforementioned points, this paper focuses on the fault analysis of five leg voltage source inverter feeding dual induction motors. The drive system is simulated using MATLAB/ SIMULINK for different pulse width modulation techniques like SPWM, SVPWM and Two Arm Modulation (TAM) Techniques. The effect on fault in the inverter like opening of the switch and shorting the switch, on the performance of the induction motors are analysed. Total Harmonic Distortion (THD) of the stator current for different modulation techniques are compared for the analysis purpose. From the results it is observed that the THD is less for SVPWM techniques as compared with SPWM and TAM method. But independent control of both the machine cannot be attained by SPWM and SVPWM method. For independent speed control TAM method is used. So a trade-off has to be done considering the requirement and THD. It is finally concluded that independent speed control is achieved at the cost of higher THD.
\end{abstract}

\section{Introduction}

Due to the various development of power electronic technology most of DC motors are replaced by economical AC motors. For industrial applications induction motors are preferred as they are of low cost, require less maintenance and high efficiency. In many industrial areas like textile, paper, cement, steel induction machine drive systems are used. The voltage source inverter (VSI) is one of the most used circuit configurations for speed control of three-phase induction motors. Inverters used for induction motor based applications are predicted to have minimum amount of lower order harmonics in the output voltage waveform. Higher order harmonic voltage distortions are filtered away by the inductive nature of the load. Engineers at all times are searching on new ways to control the motors with less cost, high efficiency and less volume of the control system. At many instants there is need to control multiple loads independently.

Conventionally, for three phase loads the control methods are of two types:

\footnotetext{
*Corresponding author: prof_sridhar6@rediffmail.com
}

a. Use of individual inverters to control the loads separately.

b. Use of single inverter to drive 2 loads.

The disadvantage of first method is that increases number of switching devices, complexity and size of the whole system.

The advantage of second method is that we can control both loads in parallel which reduces the number of switching devices, minimum losses in inverter and increase in efficiency. Considering these advantages, FLVSIs have gained attention for driving two loads. Many control methods are proposed for driving dual motor supplied by FL-VSI for improving voltage utilization factor. Some of them are two-arm modulation method, the double-zero sequence (DZS) method, space vector modulation method, direct torque control method, and hysteresis control method.

When the FLIs are used for typical drive system diagnosis of fault in the inverter becomes major important. So any failure in inverter circuit should not affect the down time of the process. Therefore, there is a need for study of the fault in the dual motor drive system which is addressed in this paper. 
The remaining part of the paper is structured as follows: Section 2 gives an overview of MATLAB based fault analysis of FL-VSI.

\section{Fault Analysis of FL-VSI Fed Dual Motor Drive System}

Fig. 1 presents the simulation circuit of the FL-VSI which can drive dual motors simultaneously. The FLVSI drive contains a DC voltage source, two asynchronous machines, and a FL-VSI. Each legs consist of two MOSFET switches. Diodes are connected across each MOSFET which ensures the negative current path to flow through it. The inverter supplied by a constant $400 \mathrm{~V}$ DC source. Switches of same leg should not be turned on at the same time because it results in short circuit of the DC supply. Switches of leg cannot be turned off all together to prevent from undefined states in VSI. Leg $\mathrm{C}$ is being common to both the motors. Phases of motor-1 (M1), A1 and B1 are connected to legs A and B of FL-VSI. Phases of motor-2 (M2) A2 and $\mathrm{B} 2$ are connected to legs $\mathrm{E}$ and $\mathrm{D}$ of FL-VSI.

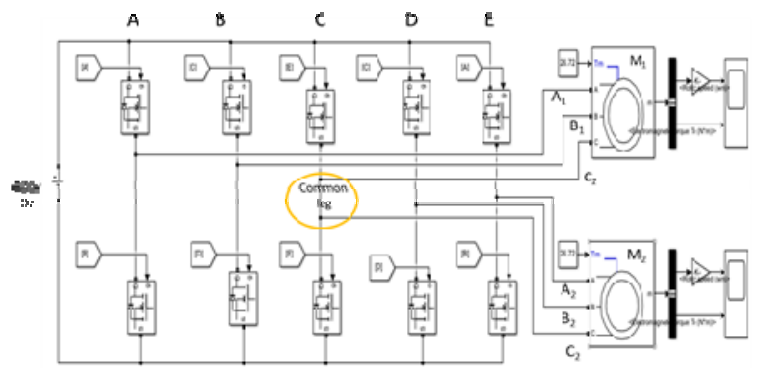

Fig. 1: Circuit configuration FL-VSI motor drive

Here fault in inverter common leg switches, such as short circuited or open circuited is analysed and THD of stator current is calculated.

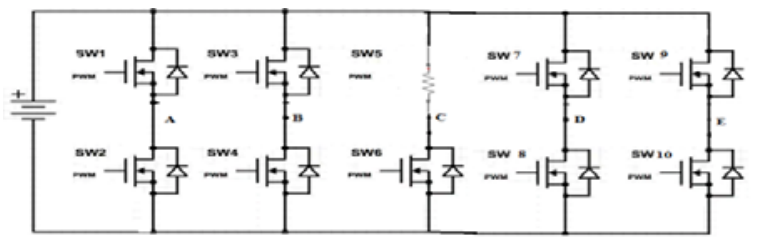

Fig. 2: Circuit Diagram of FLI with Switch SW5 is short circuited condition.

The common leg inverter switch SW5 is replaced with low value of resistance. Replacing of the low resistance with one of the ten switches in FLI is similar to short circuiting in one of the ten switches. The upper leg of phase $\mathrm{C}$ is replaced by resistance of $(1 \mu)$ ohms as seen in Fig. 2.

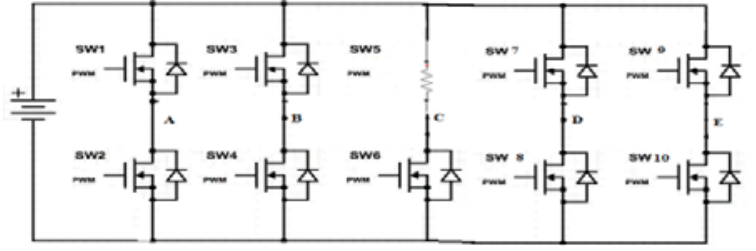

Fig. 3: Circuit Diagram of FLI with Switch SW5 is open circuited condition.

The common leg inverter switch SW5 is replaced with high value of resistance. Replacing of the high resistance with one of the switches in FLI is similar to open circuiting in one of them. Here the upper leg of phase C is replaced by resistance of $1 \mathrm{M} \Omega$. Similar procedure is done for the common leg bottom switch SW6 as depicted in Fig. 4 and Fig. 5, corresponding to open circuit and short circuit respectively

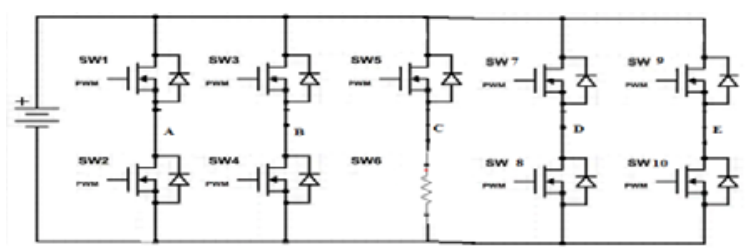

Fig. 4: Circuit Diagram of FLI with Switch SW6 is short circuited condition.

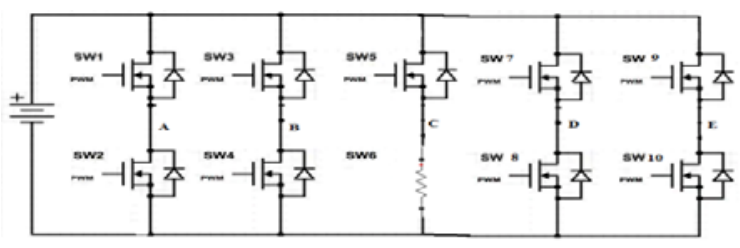

Fig. 5: Circuit Diagram of FLI with Switch SW6 is open circuited condition.

\section{FL-VSI fed dual motor drive system with different control topologies}

\subsection{SPWM Control}

Modulation is the process of varying values of carrier signal with respect to reference signal. Generally, the implementation of SPWM technique is quite easy compared to any other PWM techniques. Each switch will receive the gate signal from SPWM driver. Fig.6 shows the simulation model of FL-VSI with PWM control. Three sinusoids of $50 \mathrm{~Hz}$, having $120^{\circ}$ phase shift are compared with a carrier of $5 \mathrm{KHz}$ frequency for the generation of gating pulses. When the amplitude of the carrier is greater than the amplitude of the sinusoidal signal pulses are generated. The amplitude modulation is adjusted to 0.9 . In this way the pulses are generated to trigger MOSFETs. 

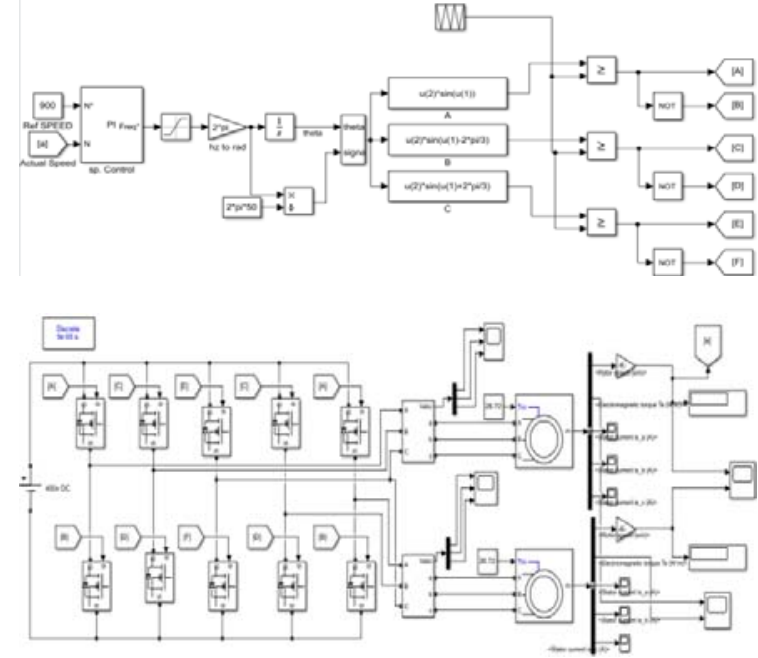

Fig. 6: Simulation of closed loop control of FLVSI with SPWM control

The switches of same leg should not turn on at the same time. NOT gate is used for complimentary switching of switches of same leg. The gating pulses A and B are given to the switches S1, S9 and S2, S10 respectively. Similarly, the gating pulses $\mathrm{C}$ and $\mathrm{D}$ are given to the switches S3, S6 and S4, S7 respectively. Finally, the gating pulses $\mathrm{E}$ and $\mathrm{F}$ are given to the switches $\mathrm{S} 5$ and S6 which is the common leg of FL-VSI.

Two identical motors of $5.4 \mathrm{HP}, 400$ volts, 6 pole, 50 Hertz, 1430 RPM and 0.8 power factor are selected for the simulation purpose. DC supply of $400 \mathrm{~V}$ is given to the inverter circuit. Two three phase motors are connected to the inverter. One leg of inverter is common for both the motors. In this general SPWM method, speed of anyone of the motors are taken as feedback signal as shown in Fig 6. The actual speed from radians to RPM is converted by multiplying with [60/ (2* pi)]. The feedback signal of 'actual speed' taken from the motor is fed to PI controller and compared with the reference speed.

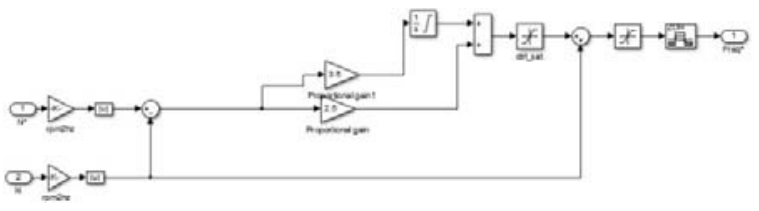

Fig. 7: PI controller system

PI controller in the circuit finds an error signal by taking the difference between reference speed and actual speed of the system. The $K_{P}$ and $K_{I}$ values are tuned and found to be 3.5 and 2.5 respectively. The saturation block is used to limit the input signal to the upper and lower limits. The error which is generated in PI controller is given to frequency control block. The frequency which is in hertz is converted into radians by multiplying it with $2 * \mathrm{Pi}$ and is given to next controlling part is as shown in Fig. 7.

3.2 SVPWM Control
The Fig. 8 shows the simulation diagram of SVPWM based FL-VSI fed dual motor drive system. An attempt has been made to simulate a five-leg voltage source inverter controlled dual induction motor drive using space vector PWM technique. This method utilizes the results of comparison of the instantaneous values of each phase voltages with a carrier waveform in order to control the switches of the five leg inverter. The MOSFET in a particular leg is switched ON whenever the amplitude of the phase voltage is greater than the carrier magnitude. There will be as many reference waveforms as the number of phases. For controlling a three phase machine, three reference waveforms mutually displaced by $120^{\circ}$ will be required. In order to increase the amplitude of the fundamental component of output voltage, a common mode voltage $\left(\mathrm{V}_{\text {offset }}\right)$ is added to the reference waveforms. This kind of control technique has the advantage of having reduced computational complexity and will results in quicker algorithm execution when implemented. The results indicated are for amplitude modulation index of 0.9 and operational frequency of $50 \mathrm{~Hz}$.
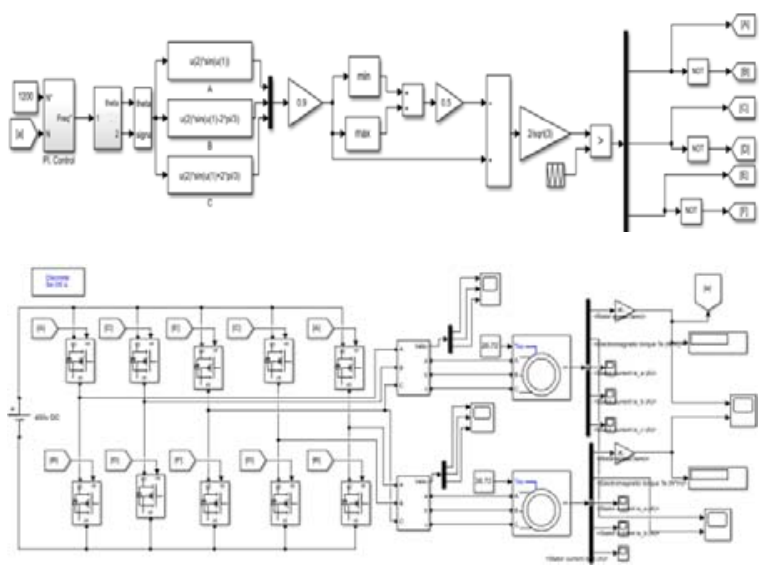

Fig. 8: Simulation of closed loop control of FLVSI with SVPWM control

In this general SVPWM with reduced computation method, speed of any one of the motors can be taken as feedback signal as shown in Fig. 8. The feedback signal of actual speed is taken from the motor is fed to PI controller and compared with the reference speed. For motors, reference speed is set to 1200 RPM as shown in Fig. 8. For the Simulation of closed loop control of FLVSI with SVPWM method the same PI controller circuit as shown in figure.7 is used with SVPWM control.

\subsection{TAM method}

The method plays an important role in case of independent control of dual motors with similar or different rated machines and overcomes all the drawbacks compared to general PWM methods. In PWM techniques, the DC bus voltage for one motor is restricted to only $50 \%$ which is one of the major 
drawback. By using this TAM method we can overcome with that problem. Fig.9 shows the simulation model of five leg voltage source inverter with TAM control. The fundamental reference sinusoidal signals of phase $V_{a 1}$ and $\mathrm{V}_{\mathrm{b} 1}$ are compared with the fundamental sinusoidal signal of phase $\mathrm{V}_{\mathrm{c} 1}$ to obtain $\mathrm{V}_{\mathrm{A}}$ and $\mathrm{V}_{\mathrm{B}}$ voltages. Similarly, the fundamental reference sinusoidal signals of phase $\mathrm{V}_{\mathrm{a} 2}$ and $\mathrm{V}_{\mathrm{b} 2}$ are compared with the fundamental sinusoidal signal of phase $V_{c 2}$ to obtain $V_{D}$ and $V_{E}$ voltages, and the common leg $\mathrm{V}_{\mathrm{C}}$ is connected to the Zero signal voltage using constant block as shown in Fig 9. The obtained sinusoidal signals are now compared with the carrier wave for the generation of the PWM pulses.

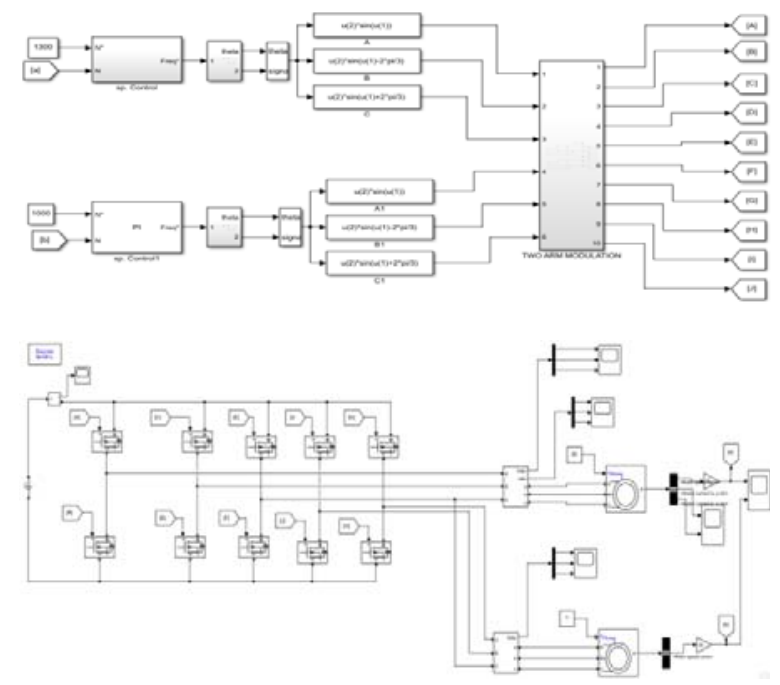

Fig. 9: Simulation of closed loop control of FLVSI with SVPWM control

The model is simulated for two cases. For first case, two identical motors of 5.4HP, 400 volts, 6 pole, $50 \mathrm{Hertz}$, 1430 RPM and 0.8 power factor are selected and for second case two different rated motors, i,e motor 1 is selected with 5.4HP, 400 volts, 6 pole, 50 Hertz, 1430 RPM and 0.8 power factor and motor 2 is selected with $10 \mathrm{HP}, 400$ volts, 6 pole, $50 \mathrm{Hertz}, 1440$ RPM and 0.8 power factor. Using TAM method gate pulses are generated for both the cases. DC supply of $400 \mathrm{~V}$ is given to the inverter circuit. The feedback signal of actual speed taken from the motor is fed to PI controller and compared with the reference speed. In first case reference speed of the motors is set to 1300 RPM and 1000 RPM respectively. In second case Reference speed of the motors is set to 1400 RPM and 800 RPM respectively. For the Simulation of closed loop control of FL-VSI with TAM method for individual motor control with respect to set reference speed the PI controller circuit is designed individually as shown in Fig.7, and it is used with TAM control.

\section{Results and Discussions}

The Inverter faults such as switch open circuit, switch short circuit conditions are simulated using MATLAB/ SIMULINK software and THD for the stator currents for both motors are observed and results are tabulated as shown in table 1 .

Table 1.Stator current THD under different fault conditions.

\begin{tabular}{|c|c|c|c|c|c|c|}
\hline \multirow{2}{*}{ Condition } & \multicolumn{2}{|c|}{$\begin{array}{c}\text { Motor- 1(stator } \\
\text { current THD) }\end{array}$} & \multicolumn{3}{|c|}{$\begin{array}{l}\text { Motor- 2(stator } \\
\text { current THD) }\end{array}$} \\
\cline { 2 - 7 } & A & B & C & A & B & C \\
\hline Healthy & 14.5 & 14.5 & 14.5 & 14.5 & 14.5 & 14.5 \\
\hline $\begin{array}{c}\text { Open Circuit fault in } \\
\text { switch E of common } \\
\text { leg }\end{array}$ & 7683 & 9550 & 5267 & 5188 & 9424 & 5267 \\
\hline $\begin{array}{c}\text { Short Circuit fault in } \\
\text { switch E of common } \\
\text { leg }\end{array}$ & 2341 & 4429 & 280.9 & 2341 & 4429 & 280.9 \\
\hline $\begin{array}{c}\text { Open Circuit fault in } \\
\text { switch F of common } \\
\text { leg }\end{array}$ & 13088 & 7400 & 5092 & 9987 & 4750 & 5096 \\
\hline $\begin{array}{c}\text { Short Circuit fault in } \\
\text { switch F of common } \\
\text { leg }\end{array}$ & 2683 & 3901 & 292.7 & 2683 & 3901 & 292.7 \\
\hline
\end{tabular}

minmminming

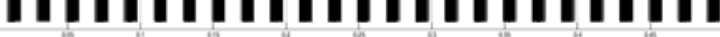

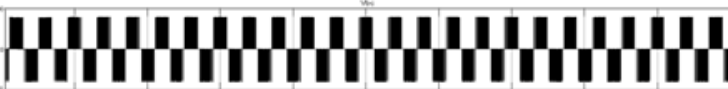

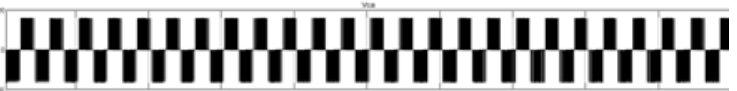

Fig. 10: Line voltages of motor-1 with SPWM control.

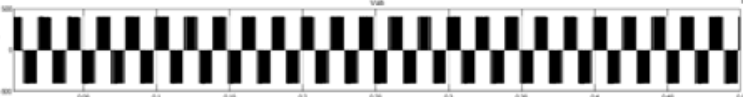

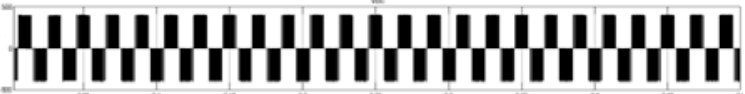 MW'mw'm,}

Fig. 11: Line voltages of motor-2 with SPWM control.

The Fig. 10 and Fig.11 shows the simulation results of line to line voltages for FL-VSI using SPWM method, feeding two motors and Fig.12 shows the speed outputs 
of both the motors. By using SPWM technique for FLVSI it is not possible to achieve independent speed control for two motors. The reference speed is set to 900 RPM.

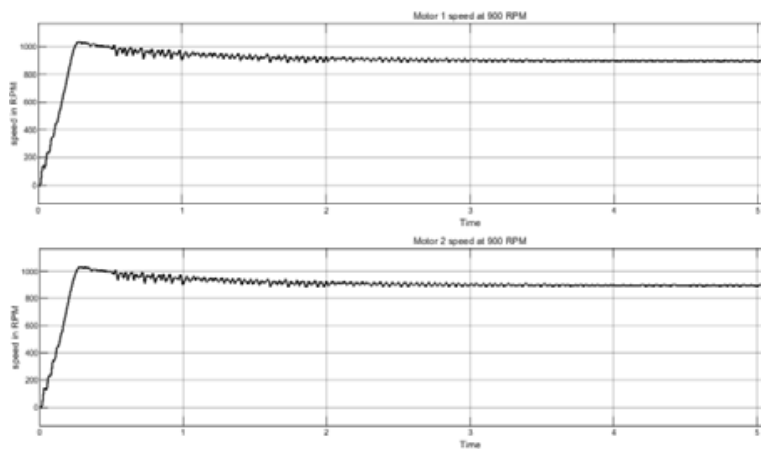

Fig. 12: Speed waveform of motor-1 and motor-2 with 900 RPM

\subsection{Results of FL-VSI Driven by SVPWM method:}

Table 2. Stator current THD under different fault conditions.

\begin{tabular}{|c|c|c|c|c|c|c|}
\hline \multirow{2}{*}{ Condition } & \multicolumn{3}{|c|}{$\begin{array}{l}\text { Motor- } 1 \text { stator } \\
\text { current THD) }\end{array}$} & \multicolumn{3}{|c|}{$\begin{array}{l}\text { Motor- } 2 \text { stator } \\
\text { current THD) }\end{array}$} \\
\hline & $\mathrm{A}$ & B & $\mathrm{C}$ & $\mathrm{A}$ & B & $\mathrm{C}$ \\
\hline Healthy & 6.5 & 6.5 & 6.5 & 6.5 & 6.5 & 6.5 \\
\hline $\begin{array}{l}\text { Open Circuit fault in } \\
\text { switch E of common } \\
\text { leg }\end{array}$ & 162.2 & 162.2 & 162 & 162.2 & 162.2 & 162 \\
\hline $\begin{array}{l}\text { Short Circuit fault in } \\
\text { switch E of common } \\
\text { leg }\end{array}$ & 19.8 & 30.1 & 18.11 & 19.8 & 30.1 & 18.11 \\
\hline $\begin{array}{l}\text { Open Circuit fault in } \\
\text { switch F of common } \\
\text { leg }\end{array}$ & 168.5 & 171.7 & 769.8 & 168.5 & 171.7 & 169.8 \\
\hline $\begin{array}{l}\text { Short Circuit fault in } \\
\text { switch F of common } \\
\text { leg }\end{array}$ & 20.57 & 31.15 & 19.23 & 320.57 & 731.15 & 19.23 \\
\hline
\end{tabular}

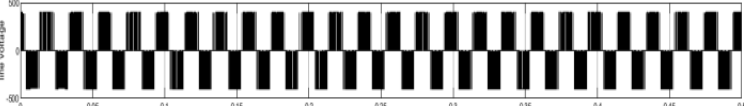

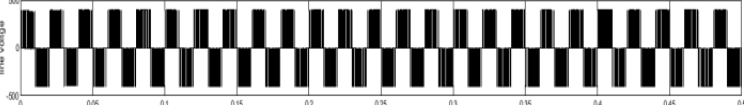

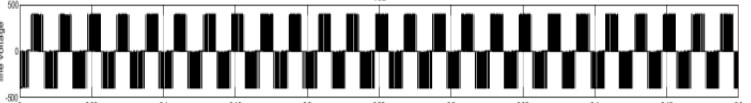

Fig. 13: Line voltages of motor-1 with SVPWM control

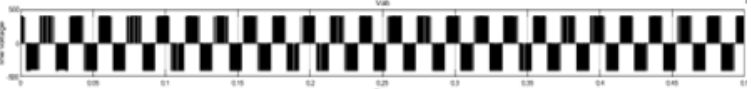

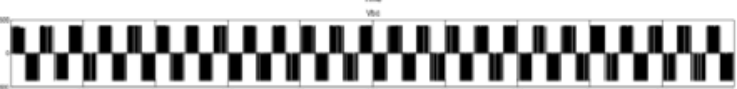

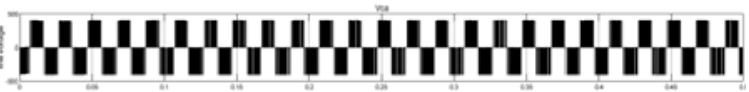

Fig. 14: Line voltages of motor-2 with SVPWM control.

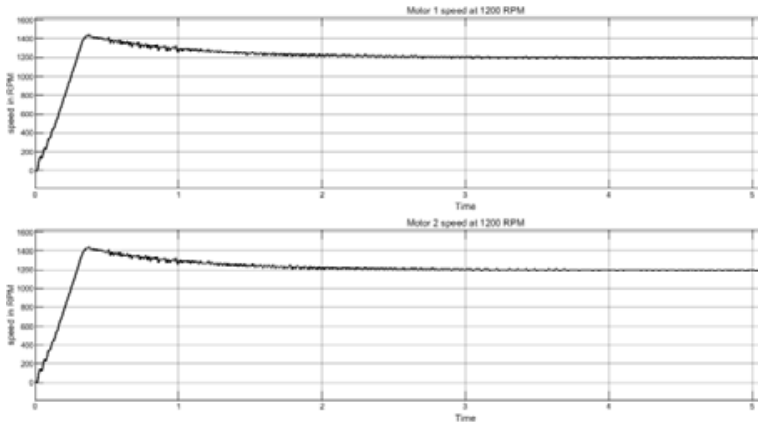

Fig. 15: Speed waveform of motor-1 and motor-2 with 1200 RPM

The Fig.13 and Fig.14 shows the simulation results of line voltages of FL-VSI using SVPWM feeding two motors and Fig. 15 shows the speed outputs of Motor 1 and Motor 2. It is observed that by using general SVPWM technique for FL-VSI we cannot achieve independent speed control of two motors. The reference speed is set to 1200 RPM.

\subsection{Results of FL-VSI Driven by TAM method:}

Table 3.Stator current THD under different fault conditions.

\begin{tabular}{|c|c|c|c|c|c|c|}
\hline \multirow{2}{*}{ CONDITION } & \multicolumn{3}{|c|}{ Motor- 1 } & \multicolumn{3}{c|}{ Motor- 2 } \\
\cline { 2 - 7 } & A & B & C & A & B & C \\
\hline Healthy & 65.7 & 65.7 & 65.7 & 65.7 & 65.7 & 65.7 \\
\hline $\begin{array}{c}\text { Open Circuit } \\
\text { fault in switch } \\
\text { E of common } \\
\text { leg }\end{array}$ & 9.5 & 9.2 & 8.8 & 9.5 & 10.2 & 47.7 \\
\hline $\begin{array}{c}\text { Short Circuit } \\
\text { fault in switch } \\
\text { E of common } \\
\text { leg }\end{array}$ & 1693 & 72.2 & 1685 & 1772.7 & 2106.7 & 92.5 \\
\hline $\begin{array}{c}\text { Open Circuit } \\
\text { fault in switch F } \\
\text { of common leg }\end{array}$ & 10 & 10 & 9.9 & 24.5 & 41 & 17.8 \\
\hline $\begin{array}{c}\text { Short Circuit } \\
\text { fault in switch F } \\
\text { of common leg }\end{array}$ & 1584 & 2409 & 90.3 & 1584 & 2409 & 90.3 \\
\hline
\end{tabular}




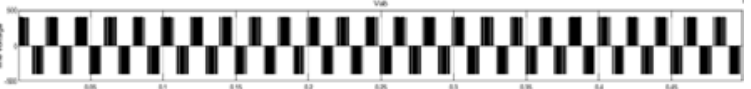

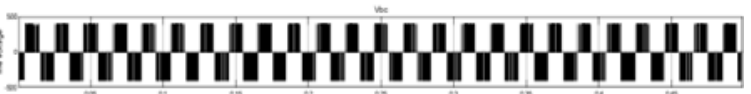

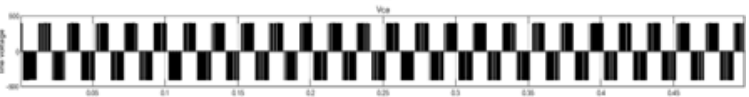

Fig. 16: Line voltages of motor-1 with TAM control.

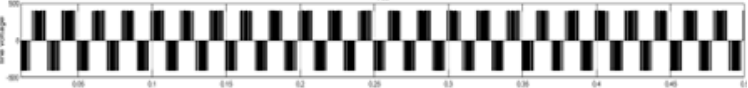 MMMmmimm MmMmmmom}

Fig. 17: Line voltages of motor-2 with TAM control

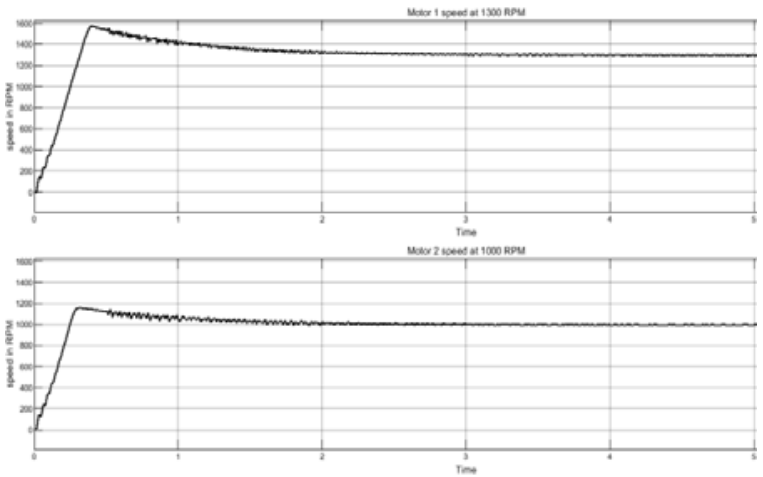

Fig. 18: Speed waveform of motor-1and motor-2 with 1300 RPM and 1000 RPM

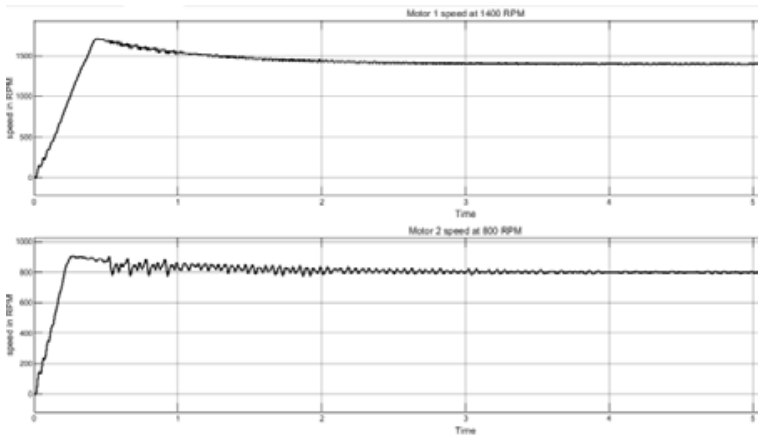

Fig. 19: Speed waveform of motor-1and motor-2 with 1400 RPM and 800 RPM.

The Fig 16 and 17 shows the line voltages of motor 1 and motor 2 and figure 18 shows speed output waveform of FL-VSI driven by TAM Method for same rated motors. The main advantage of using this TAM method is to control dual inductions motors with independent speed.
In the first case the model is simulated by considering same specifications for both the motors. For Motor 1 the reference speed is set to 1300 RPM and Motor 2 is set to 1000 RPM, the reason behind this is to show experimentally, by using TAM method we can achieve independent speed control for two motors and results are obtained as shown in Fig.18. In the second case simulation was carried out for different machine ratings, that is motor 1 is selected with 5.4HP, 400 volts, 6 pole, 50 Hertz, 1430 RPM, 0.8 power factor and that of motor 2 it is selected with $10 \mathrm{HP}, 400$ volts, 6 pole, 50 Hertz, 1440 RPM, 0.8 power factor. Here for motor 1 the reference speed is set to $1400 \mathrm{RPM}$ and motor 2 is set with 800 RPM as a reference speed. The Fig. 19 shows the results of TAM method for independent control of two different rated induction motors.

From Table. 1, $2 \& 3$ it is observed that during the fault condition, the THD values go very high in some cases, indicating that all the frequency components are present in the stator current during that particular fault condition.

\section{Conclusion}

In the proposed work the drive system is simulated using different pulse width modulation techniques like SPWM, SVPWM and TAM Techniques. Effect of fault in the inverter like opening of the switch and shorting the switch, on the performance of the motors are analysed. The output phase voltages and speed of dual motors are simulated using MATLAB/SIMULINK software. From the results it is observed that the THD is less for SVPWM techniques as compared with SPWM and TAM method for health condition, but independent control of both the machine cannot be attained. For independent speed control TAM method is used. So a trade-off is made considering the requirement and THD. It is finally concluded that independent speed control is achieved at the cost of higher THD. The output phase voltages and speed of dual motors are simulated using MATLAB software, and results are obtained. In order to overcome or reduce with faulty conditions various fault tolerance methods can be implemented so that it should not affect the down time of the process.

\section{Acknowledgement}

This research is funded by M S Ramaiah Institute of Technology under RIT seed funding number 2020/RIT/R\&D/IF/062. The authors express their gratitude towards the institution for providing the support in this study.

\section{References}

1. Ahmad Anad Abduallah, Mohammed Meraj, Mohammed Al- Hitmi, Atifiqbal, "Space vector pulse width modulation control techniques for a five- phase quasi-impedance source inverter" 2017. 
2. Young-Seol Lim, Student Member, IEEE, JuneSeok Lee, Member, IEEE, and Kyo-Beum Lee, Senior Member, IEEE “Advanced Speed Control for a Five-Leg Inverter Driving a Dual-Induction Motor System", 2019.

3. M. Jones S.N. Vukosavic D. Dujic E. Levil P. Wright1School of Engineering, Liverpool John Moores University, "Five-leg inverter PWM technique for reduced switch count two-motor constant power applications" Liverpool L3 3AF, UK, Department of Electrical and Electronic Engineering, University of Belgrade, Belgrade 11000, Serbia, 2007.

4. Gui-Jia Su and John S. Hsu National Transportation Research Center Oak Ridge National Laboratory Knoxville, TN, "A Five-Leg Inverter for Driving a Traction Motor and a Compressor Motor", 2016.

5. E. C. dos Santos Jr., C. B. Jacobina, O. I. da Silva and A. M. N. Lima Departamento de Engenharia El'etrica Universidade Federal de Campina Grande Campina Grande - PB - Brazil, "Two Motors Drive System Topologies with Five-Leg Inverter”, 2012.

6. Yashan Hu, Shoudao Huang, Senior Member, IEEE, Xuan $\mathrm{Wu}$ and XuefeiLi"Control of Dual ThreePhase Permanent Magnet Synchronous Machine Based on Five-Leg Inverter" 2019.

7. Sherif M. Dabour, Mahmoud I. Masoud, Department of Electrical Power and Machines Engineering, Egypt "Open-Circuit Fault Detection of Five-Phase Voltage Source Inverters" Tanta University, 2015.

8. Yang Mei, ShuaiweiFeng" An Optimized Modulation Method for a Five-Leg- Inverter for Dual Induction Motor Drives" Beijing North China University 2016.

9. M.H.N.Talib, Z.Ibrahim, N.AbdulRahim, A.S.AbuHasim "Analysis on Speed Characteristics Of Five Leg Inverter for Different Carrier Based PWM Scheme" 2012.

10. K. Gopakumar, S. Sathiakumar, S. K. Biswas, and J. Vithayathil,"Modified current source inverter fed induction motor drive with reducedtorque pulsations," IEE Proc. B Elect. Power Appl., vol. 131, no. 4, pp.159-164, 1984. 